\title{
The Effects of Specific Drills on the Flip Turns of Freestyle Swimmers Based on a Kinesiology Analysis
}

\author{
by \\ Yuhong Wen ${ }^{1}$, Yi Peng ${ }^{1}$, Feng Zhao ${ }^{2}$, Kexin Zhen ${ }^{1}$
}

\begin{abstract}
This research aimed to define the key factors in freestyle flip turns via a kinesiology analysis to diagnose swimmers. Hence, specially designed drills were created to improve swimmers' flip-turn skills and assess the effects of training. Nine Chinese national modern pentathlon athletes ranging in age from 20 to 26 years with an average of 10 years of training experience were tested and trained in this study. The Kistler Performance Analysis System for Swimming was used for the pre-and post-test analyses. A kinesiology analysis of the data from the pre-test was used for the diagnosis and specific drills were adopted for 10 weeks, 3 times per week before the post-test. The comparison of the pre- and post-test performances was used to assess the effects of training. After 10 weeks of specific drill training for flip turns, participants' turning skills significantly improved. Speed in approaching, somersaulting, pushing-off and gliding all increased. The angles of the knees and hips as well as the force applied improved, which contributed to swimmers' increased speed. Since the skills needed for a flip turn are complex and not easily diagnosed via observation alone, this kinesiology analysis will make diagnosis objective and easy.
\end{abstract}

Key words: flip turn, freestyle, kinesiology, drills, effect.

\section{Introduction}

It is important for swimmers to possess excellent turning skills, especially in distance swimming. Freestyle swimmers spend 20 to $38 \%$ of their time turning in short-course races and improving turning can decrease race time by at least $0.20 \mathrm{~s}$ per length (Maglischo, 2003, Slawson et al., 2011). The most difficult process in turn training is diagnosis because the turn is complex (i.e., it contains different parts and must be completed within a brief period of time). A thorough analysis on turns and practice enabled Chinese Olympic champion Sun Yang to improve in turning, especially in tuck speed. This improvement contributed to his success at the 2012 Olympic Games (Zhang, 2013). A kinematic analysis is a popular method for examining different swimming techniques and several software programs (e.g., Dartfish) have been developed to digitalize parameters for practical use (Li, 2013). Some competitive swimming research organizations have adopted the Kistler Performance Analysis System for Swimming and this system has been recognized as being relatively accurate and fit for a swimming technique data collection and analysis. Most of this research is based on the data collected using the Kistler system (Hazrati et al., 2014). Although some studies have focused on the kinetic analysis of swimming turn characteristics for different strokes, only few studies have examined how to improve swimmers' turning skills on a practical basis; this lacuna is a priority for coaches and swimmers. The current research sought to define the key factors in freestyle flip turns via kinesiology analysis to diagnose swimmers. This project aimed to improve swimmers' flip turn skills and assess the effects by systematically designing and using specific drills.

1 - Beijing Sport University,Beijing, China.

2 - Zhejiang University, Hangzhou, China. 


\section{Material and Methods}

\section{Participants}

Nine Chinese national modern pentathlon athletes aged from 20 to 26 years with an average of 10 years of training experience participated in this study. The sample included 5 males and 4 females. All participants were elite athletes in modern pentathlon, and 3 of them were medalists in the World Championships.

\section{Method}

The Kistler Performance Analysis System for Swimming was adopted for the pre and post-test evaluations. Five high-speed cameras were placed in the experimental setup: 4 underwater and 1 on deck. Underwater cameras were set at 2, 5, 10 and $15 \mathrm{~m}$ from the pool wall. A turning force plate was installed on the wall to collect data such as foot contact duration. The data from the first test as well as those from the observations and analyses were used as a basis to identify and design specific drills.

Ten weeks of specific training were planned and executed under the strict supervision of researchers and coaches, and drills were performed 3 times per week. The post-test evaluation followed the same pattern as the pretest evaluation, but performed after 10 weeks of training. A comparison of the performance at the pre and post-tests was used to assess the effect of training. Each participant was tested 3 times in both the pre- and post-tests, and the fastest times were used for further analysis. Paired comparison tests were applied to examine statistical significance.

The parameters collected included:

- times for the $15 \mathrm{~m}$ turn, starting when the swimmer' head was $5 \mathrm{~m}$ from the wall until the head was $10 \mathrm{~m}$ away from the wall after the turn;

- times for the $10 \mathrm{~m}$ turn, starting when the swimmer' head was $5 \mathrm{~m}$ from the wall until the head was $5 \mathrm{~m}$ away from the wall after the turn;

- times for $5 \mathrm{~m}$ to touch, starting when the swimmer' head was $5 \mathrm{~m}$ from the wall until the feet touched the wall after the flip turn;

- foot contact duration, starting when the swimmer' feet touched the wall to when the swimmer left the wall after the flip turn;

- somersault times, starting when the top of the head was vertical to the bottom until when the feet left the wall after the flip turn;

- time from touch to $5 \mathrm{~m}$, starting when the swimmer' feet touched the wall until the head was $5 \mathrm{~m}$ away from the wall after the turn;

- projection angle off the wall, angle in degrees of the pushing-off force and the horizontal line;

- angle of the knees during the push-off;

- angle of the hips during the push-off;

- distance of the 1st dolphin kick in meters starting from the wall until the 1st dolphin kick;

- distance in meters of the head in the deepest position, starting from the wall until when the head was in the deepest position; and

- maximum depth of the head (m) from the water surface to the head when the head was in the deepest position.

\section{Results}

Kinesiology indices such as times and angles were chosen for comparison in the pre- and posttests as they are original and direct indicators of speed and shape.

The results in Table 1 show that the time of the flip turns significantly decreased; thus, participants' turning speed improved. The mean approach time decreased from 3.51 to $3.41 \mathrm{~s}$ ( $\mathrm{p}<$ $0.05)$; the somersault time decreased from 0.45 to $0.42 \mathrm{~s}(\mathrm{p}<0.01)$; the pushing-off time for $5 \mathrm{~m}$ decreased from 2.15 to $2.04 \mathrm{~s}$ ( $\mathrm{p}<0.05$ ), and the time of a 5-m round-trip turn decreased from 5.62 to $5.45 \mathrm{~s}(\mathrm{P}<0.01)$.

The results in Table 2 show that the angles of the knees and hips as well as the force applied changed significantly and these factors contributed to the speed increase in the turn. Knee and hip angles both increased, indicating that participants' bodies were more streamlined during the push-off after training $(\mathrm{p}<0.01$ and $\mathrm{p}<$ 0.05). The push-off angle also changed significantly $(p<0.01)$, leading to a more appropriate direction after the somersault and during push-off.

\section{Discussion}

\section{Diagnosis of flip turn skills among participants}

Diagnoses were made after the pre-test and participants' mistakes in flip turns were listed. The turning was divided into 4 phases for the purpose of diagnosis: approach, somersault and push-off, underwater gliding and breakout. 


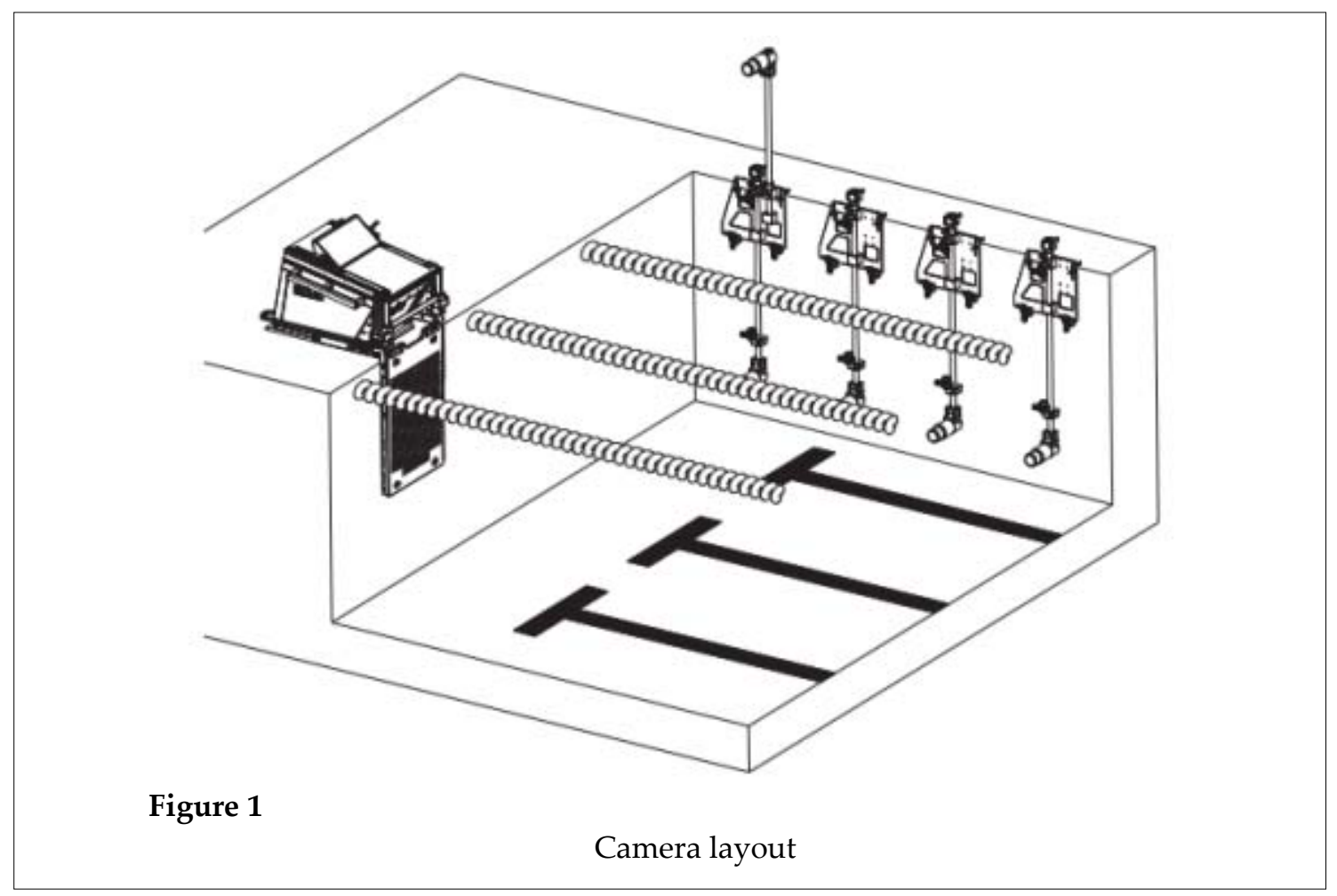

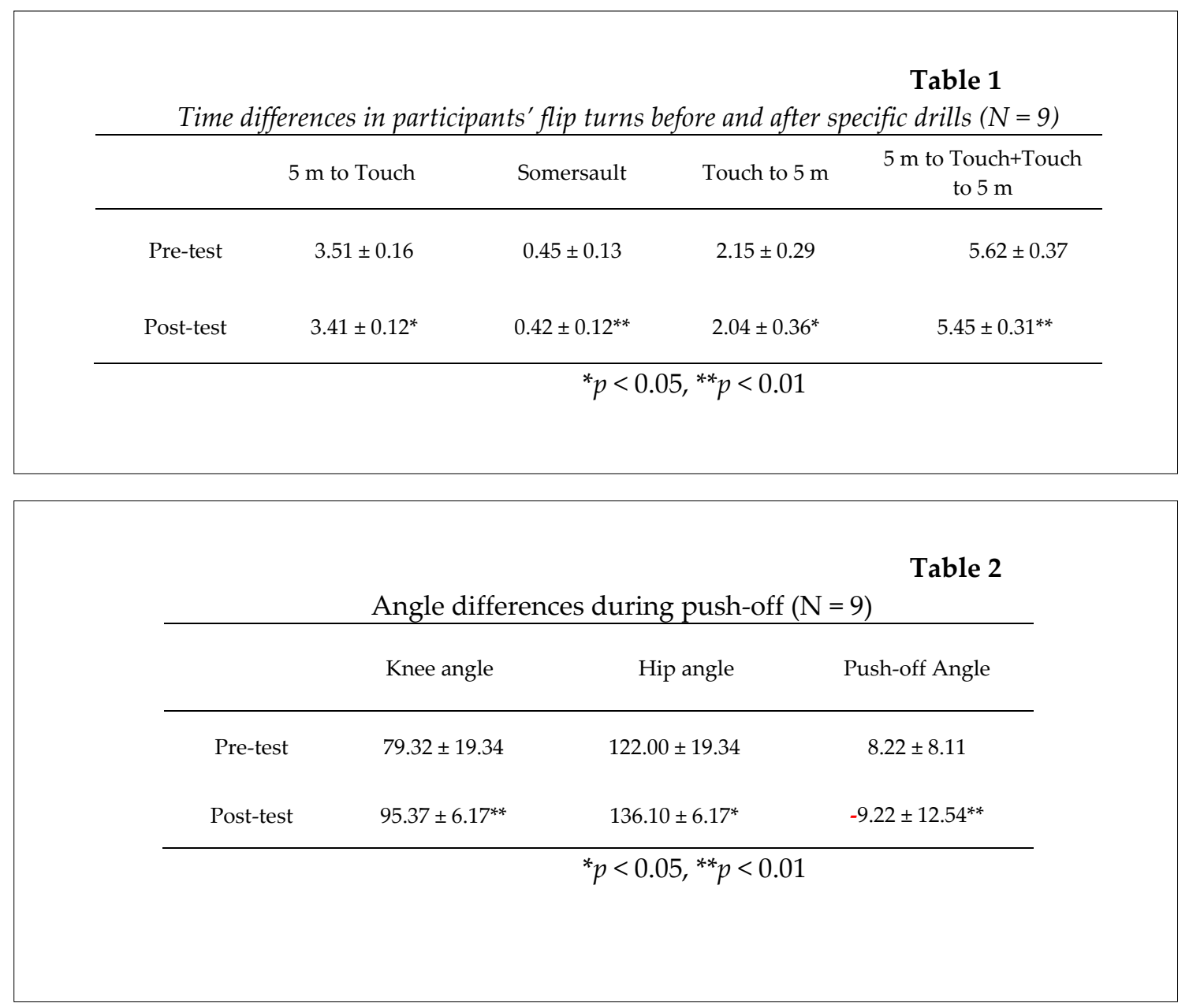


Table 3

Drills used to improve turning skills during the somersault and push-off periods

\begin{tabular}{|c|c|c|}
\hline Drills & Description & Tips \\
\hline $\begin{array}{l}\text { Tucking into a } \\
\text { tight ball from a } \\
\text { standing } \\
\text { position }\end{array}$ & $\begin{array}{l}\text { Standing in the water and sculling the } \\
\text { water with hands; tucking the body } \\
\text { tightly and somersaulting quickly, } \\
\text { then standing again }\end{array}$ & $\begin{array}{l}\text { Thighs should touch the chest, } \\
\text { and the chin should be near the } \\
\text { knees; the knees should be bent, } \\
\text { and the body should be tucked } \\
\text { into a tight ball. }\end{array}$ \\
\hline $\begin{array}{l}\text { Tucking and } \\
\text { somersaulting } \\
\text { while } \\
\text { swimming }\end{array}$ & $\begin{array}{l}\text { Swimming quickly, then tucking } \\
\text { tightly following the somersault and } \\
\text { then standing up }\end{array}$ & $\begin{array}{l}\text { Use the momentum of } \\
\text { swimming to start the } \\
\text { somersault; thighs should touch } \\
\text { the chest and the chin should be } \\
\text { near the knees; the knees should } \\
\text { be bent and the body should be } \\
\text { tucked into a tight ball. }\end{array}$ \\
\hline Accelerating & & \\
\hline $\begin{array}{l}\text { and } \\
\text { somersaulting } \\
\text { with feet } \\
\text { touching the } \\
\text { wall from the } \\
\text { correct } \\
\text { positions and } \\
\text { angles }\end{array}$ & $\begin{array}{l}\text { Standing } 10 \mathrm{~m} \text { from the wall and } \\
\text { swimming quickly toward the wall; } \\
\text { starting the somersault until the feet } \\
\text { touched the wall from the correct } \\
\text { positions and angles }\end{array}$ & $\begin{array}{l}\text { Adjust the stroke rhythm as the } \\
\text { head passes the T line on the } \\
\text { bottom with the skills learned } \\
\text { before; as the feet touch the } \\
\text { wall, the body should be } \\
\text { stretched out and in a line. }\end{array}$ \\
\hline
\end{tabular}

\section{Table 4}

Time of somersault and foot contact duration before and after training

\begin{tabular}{|c|c|c|}
\hline & Somersault & $\begin{array}{l}\text { Foot contact } \\
\text { duration }\end{array}$ \\
\hline Pre-test & $0.4467 \pm 0.13$ & $0.3421 \pm 0.03$ \\
\hline Post-test & $0.4167 \pm 0.12^{*}$ & $0.3320 \pm 0.02$ \\
\hline
\end{tabular}

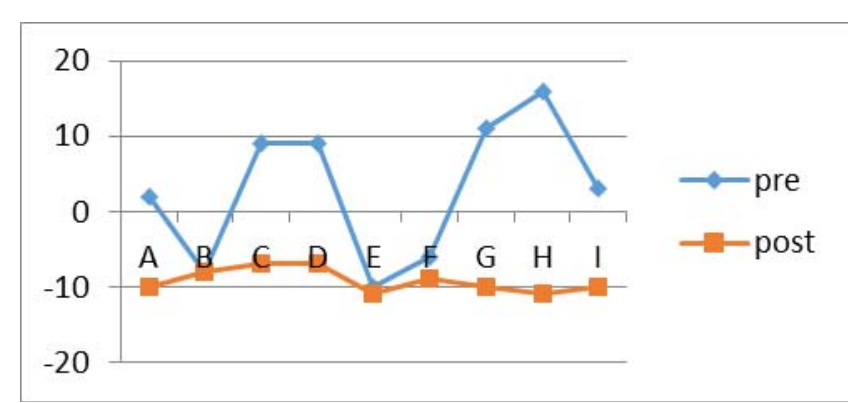

Figure 2

Projection angles off the wall of the 9 participants before and after training

(A-I refers to the 9 participants) 


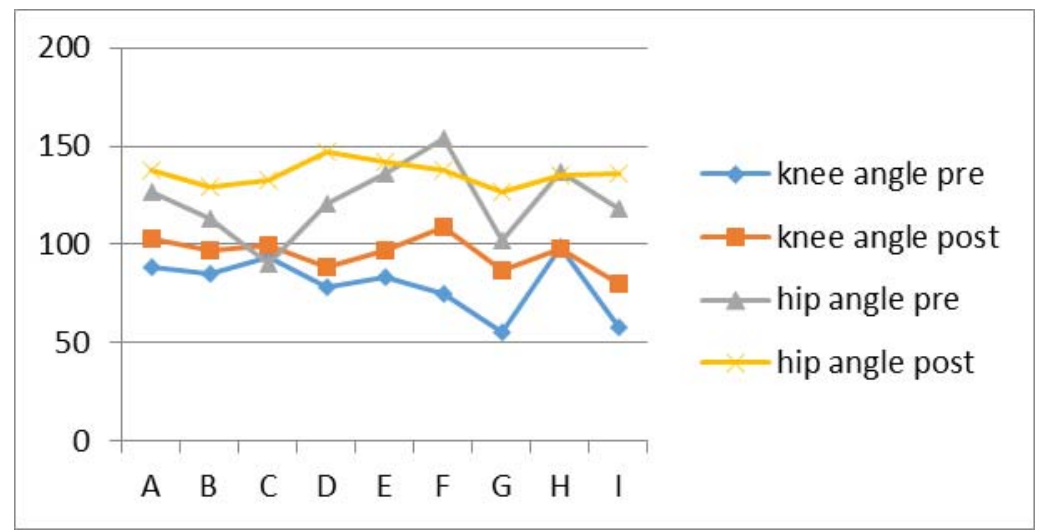

Figure 3

Knee and hip angles of the 9 participants before and after training (A-I refers to the 9 participants)

\section{Table 5}

Drills used to improve turning skills during the underwater gliding period

\begin{tabular}{|c|c|c|}
\hline Drills & Description & Tips \\
\hline $\begin{array}{l}\text { Pushing-off } \\
\text { with a stretched } \\
\text { and streamlined } \\
\text { position }\end{array}$ & $\begin{array}{l}\text { Push-off the wall as forcefully as } \\
\text { possible, arms stretched as long as } \\
\text { possible with hands overlapped, legs } \\
\text { and feet stretched and clipped }\end{array}$ & $\begin{array}{l}\text { Imagine and imitate the shape } \\
\text { of a pencil. Use the momentum } \\
\text { of the push-off to glide as far as } \\
\text { possible. }\end{array}$ \\
\hline $\begin{array}{l}\text { Pushing-off } \\
\text { followed by fast } \\
\text { underwater } \\
\text { dolphin kicks }\end{array}$ & $\begin{array}{l}\text { Based on the previous drill, perform } \\
\text { dolphin kicks underwater after } \\
\text { streamline gliding }\end{array}$ & $\begin{array}{l}\text { Use the momentum of the push- } \\
\text { off and glide to maintain a } \\
\text { streamlined position and kick } \\
\text { quickly. }\end{array}$ \\
\hline $\begin{array}{l}\text { Pushing off the } \\
\text { bottom of the } \\
\text { pool and } \\
\text { performing } \\
\text { dolphin kicks }\end{array}$ & $\begin{array}{l}\text { Crouch down underwater and push } \\
\text { vertically up from the bottom of the } \\
\text { pool followed by dolphin kicks }\end{array}$ & $\begin{array}{l}\text { Push forcefully and pierce the } \\
\text { body out of the water surface as } \\
\text { high as possible like a rocket. }\end{array}$ \\
\hline
\end{tabular}

Table 6

The distance between when the $1^{\text {st }}$ dolphin kick began and when participants' heads were in the deepest position as well as the deepest depth of their heads (m)

\begin{tabular}{cccc}
\hline & $\begin{array}{c}1^{\text {st }} \text { dolphin kick } \\
\text { begins }\end{array}$ & $\begin{array}{c}\text { Heads in } \\
\text { deepest } \\
\text { position }\end{array}$ & $\begin{array}{c}\text { Maximu } \\
\text { m depth of } \\
\text { head }\end{array}$ \\
\hline Pre-test & $1.05 \pm 0.11$ & $2.74 \pm 0.66$ & $0.62 \pm 0.43$ \\
Post-test & $1.36 \pm 0.19^{* *}$ & $2.76 \pm 0.68$ & $0.45 \pm 0.56^{*}$ \\
\hline & ${ }^{* *} p<0.01 ;^{*} p<0.05$
\end{tabular}




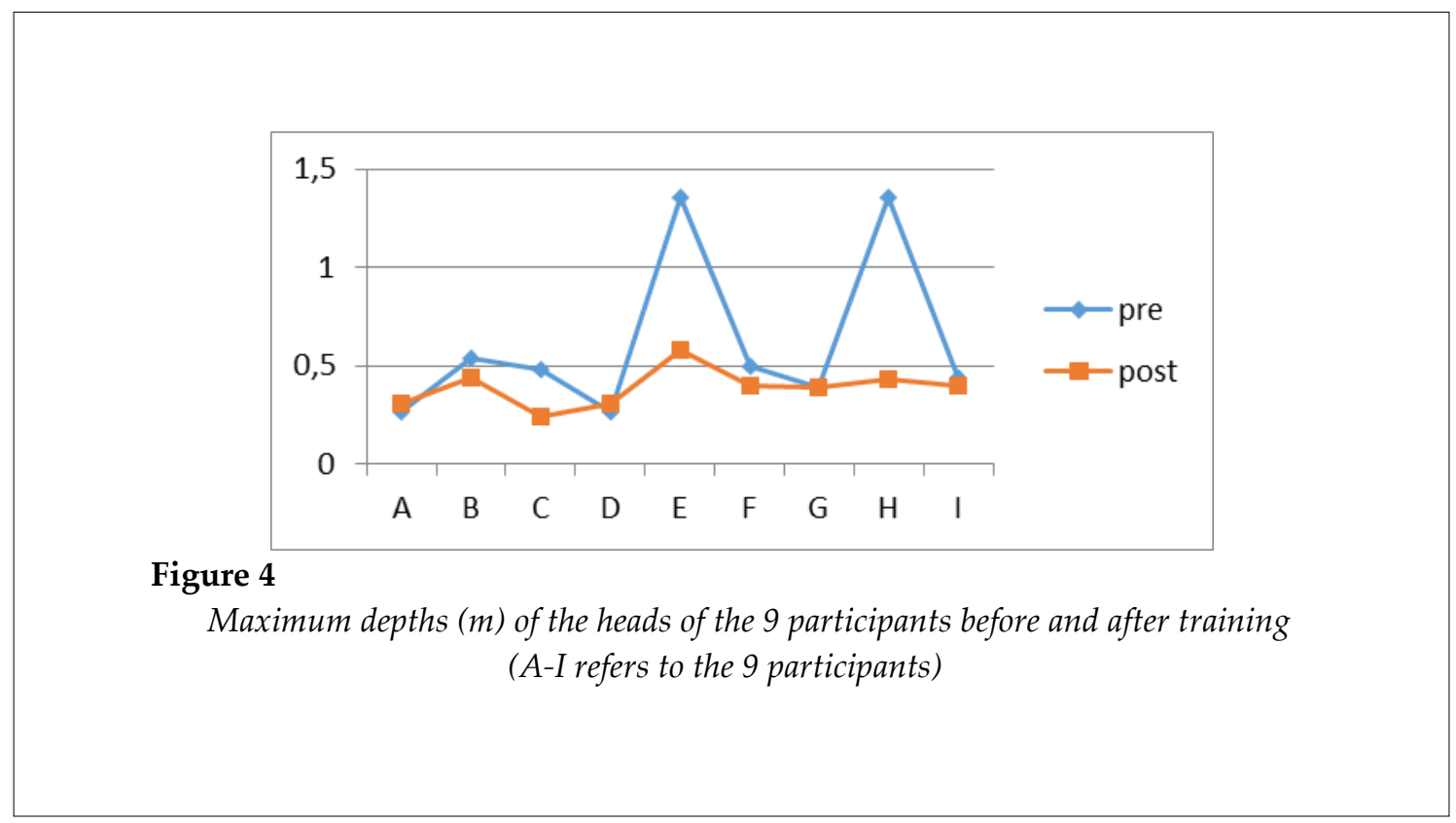

Compared with Australian elite swimmers, the participants' turn times were relatively longer; thus, they were much slower than these elite swimmers (Mason, 2015). For example, the $5 \mathrm{~m}$ to touch time of the Australian elite swimmers was $2.69 \mathrm{~s}$ for males and $3.03 \mathrm{~s}$ for females, whereas the touch to $5 \mathrm{~m}$ time was $1.68 \mathrm{~s}$ for males and $1.97 \mathrm{~s}$ for females. These times were much shorter than those recorded by the participants in the current study (mean $5 \mathrm{~m}$ to touch time $=3.51 \mathrm{~s}$; mean touch to $5 \mathrm{~m}$ time $=2.15 \mathrm{~s}$ ).

Combining the data with observations and image analysis, the participants' major errors and shortcomings were uncovered. The defects in their approaching phase included decelerating before approaching, raising the heads before approaching and pausing to prepare for the somersault. During the somersault and push-off phases, participants did not always tuck their bodies tightly during the somersault and began to somersault too early or too late. They did not keep their arms, trunks and legs in line and they did not stretch out when their feet touched the wall. Most of the swimmers employed the wrong hip angle before the push-off. During the underwater gliding and breakout period, the participants did not keep a streamlined position and dove into the water too deeply.

Approximately $89 \%$ of the participants decelerated before approaching the walls with a slower stroke rate, whereas the top world swimmers show a faster speed of approach than their average swimming speed (Zheng, 2010). This decrease in speed was likely caused by decreases in both kicking and arm-stroke frequency.

All of the participants raised their heads before somersaulting as they were trying to judge and adjust the timing for their flip turns; this decision resulted in a decrease in speed. Approximately $44 \%$ of participants did not achieve appropriate turning timing (e.g., one arm recovered through the air, but returned to the legs again).

During the somersault and push-off period, 78\% of the participants did not tightly tuck their bodies, resulting in a loss of speed (Zhu, 1992). All participants began somersaulting in the wrong position, either too early or too late, which resulted from the knees bending too much or being too straight to push-off forcefully. When the feet were touching the wall, most of the participants' bodies were not in line. Furthermore, their foot touching time on the wall was much longer than that of elite swimmers.

\section{Specific drills designed to improve turn skills}

Specific drills were designed after the diagnoses were made. Drills and training plans followed a detailed discussion between the researchers and coaches. Training lasted 10 weeks. The drills included memorizing the stroke counts after the underwater $\mathrm{T}$ signals and accelerating before 
touching; tucking into a tight ball from a standing position and during swimming; accelerating and somersaulting with the feet touching the wall in the correct positions and with correct angles; pushing-off in a stretched and streamlined position; pushing-off followed by fast underwater dolphin kicks; and pushing the bottoms and using dolphin kicks. Drills were practiced 3 times per week and consistent evaluations and feedback were provided for swimmers to comprehend and practice.

To improve the swimmers' skills during the approaching period, a reference control drill was adopted. Participants were asked to accelerate 10 $\mathrm{m}$ from the wall and remember their stroke counts as their head passed the $\mathrm{T}$ line ( $5 \mathrm{~m}$ from the wall) until the somersault began. Coaches and researchers observed and provided constant feedback during practice until the participants never raised their heads before somersaulting and were able to execute the move in the correct amount of time. The results in Table 1 show that the approach time was significantly reduced after training $(p<0.01)$.

Numerous researchers and high-level swimming coaches consider approach speed as important in turning (Maglischo, 2003; Mason and Cossor, 2000; Yang, 2003); however, swimmers often neglect it. Although the current participants were high-level swimmers, modern pentathlon athletes must also cope with sporting events such as running, fencing, riding and shooting. The time spent on swimming training is limited; thus, the athletes seldom focus on their turning skills. The pre-test results showed that the athletes had potential to improve their turning skills. The aforementioned drills were efficient in making the participants aware of the importance of their stroke count to specific signals and of maintaining their speed when approaching the turn. Furthermore, through observation and emphasis, they did not raise their head before the somersault, which helped make quick turns.

To improve the athletes' turning skills during the somersault and push-off periods, 3 drills were designed and practiced: tucking into a tight ball from a standing position; tucking into a tight ball while swimming; and accelerating and somersaulting from the correct positions and angles with the feet touching the wall.

The results in Table 4 show that participants' somersault time was reduced significantly after practicing the specific drills $(p<0.05)$. Chinese elite distance swimmers also showed improved turning speeds after a similar practice program. Olympic champion Sun Yang shortened his 7 turns by $1.28 \mathrm{~s}$ in the $400 \mathrm{~m}$ freestyle (Zhang, 2013).

The 3 drills shown in Table 3 aimed to increase somersault speed step by step. Beginning with a relatively simple task, participants were asked to concentrate on tucking their bodies into tight balls when somersaulting from a standing position. A classified and easy standard was set for the participants to evaluate their movement as they made sure their thighs were touching their chests and their chins were near their knees. Additional training focused on making a quick, tight flip following the acceleration due to swimming. In addition to the same standard, the participants made use of this momentum by accelerating and somersaulting continuously. In the end, participants combined accelerating, tucking and somersaulting with a perfect foot touch on the wall, not only in the correct position, but also at the appropriate angle.

Participants' foot contact duration was also reduced, but not to a significant degree $(p>0.05)$. This slight reduction might have contributed to the enhancement in turns. To increase push-off speed and force, participants were given a special drill that instructed them to crouch under the water and push off the bottom as soon as possible. This drill ensured that the swimmers were aware to push off immediately after touching the wall.

In addition to time, the projection angle off the wall was important in assessing the athletes' turns. Before training, participants' projection angles off the wall were $8.22 \pm 8.11$ degrees, indicating that most of the participants pushed off upward, which was not successful for gliding or dolphin kicking and exhibited large individual differences (Figure 2). After training, the angles were $-9.22 \pm 12.54$ degrees, much better for gliding and dolphin kicking. According to Mason et al. (2015), the projection angle off the wall of elite swimmers ranges from -10 to -12 degrees. The participants' angles after training were similar to those of elite swimmers.

The knee and hip angles also changed significantly after training (Table 2 and Figure 3), which shows that participants were able to judge the starting time of their turns more precisely. 
Furthermore, the participants were able to perform a somersault and control their body position more reasonably after specific drill training.

To improve skills during the underwater gliding period, 3 specific drills were designed and administered.

Participants' times from push-off to $5 \mathrm{~m}$ were reduced $(p<0.05)$ after practice (Table 1$)$. Their gliding distance also increased significantly (Table $6)$.

The gliding distance was relatively brief in the first test; thus, the participants were weak on push-off force and streamlined gliding. Specific drills improved their pushing power and the streamlined gliding. The distance of the first dolphin kick from the wall greatly increased after training $(p<0.05)$. Researchers also found that most participants were not able to control their gliding depth appropriately (i.e., they were too deep in the water before the specific drill training; Figure 4). Some of the participants' maximum head depths were as deep as $1.36 \mathrm{~m}$, leading to a great velocity decrease during gliding. This fluctuation in the water caused increased drag during push-off and decreased speed (Lyttle et al., 1999). In the pre-test, 2 participants' maximum head depths were more than $1 \mathrm{~m}$ under the water, indicating that they were unable to control their body position successfully, leading to increased water resistance. The drills practiced by the participants helped to control their body positions, especially pushing up from the bottom of the pool and performing dolphin kicks, both of which require ideal streamlining and a tight body to avoid dropping down after pushing. After this specific training program, the participants were able to control their head and body positions much better. As Lyttle indicated (1999), swimmers should push-off the wall when approximately 0.4 $\mathrm{m}$ deep and maintain this glide depth for approximately $0.5 \mathrm{~m}$ for maximum drag reduction benefits at faster velocities. The participants' maximum head depths were too deep before training, but were much more appropriate after training $(p<0.05)$.

Although the participants had improved after practice, their performance was far from perfect or stable.

\section{Conclusions}

After 10 weeks of specific drill training for flip turns, participants' turning skills significantly improved. Their speeds in approaching, somersaulting, pushing-off and gliding all increased. The angles of their knees and hips as well as the force applied improved, which contributed to the increase in speed. The skill required for a flip turn is complex and not easy to diagnose solely based on observation; thus, the current kinesiology analysis sought to increase the objectiveness and precision of this diagnosis.

\section{Acknowledgements}

Kistler China Limited of Kistler Group provided help during the research. Coaches and athletes of Chinese modern pentathlon were really cooperative during the process of research. The researchers appreciate the support and help very much.

\section{References}

Chow JW, Hay JG, Wilson BD, Imel C. Turning techniques of elite swimmers. J Sports Sci, 1984; 2(3): 241-255

Hazrati P, Mason BR, Sinclair PJ, Sacilotto G. Development of a new resisted technique in active drag estimation. Proceeding of the IX International Symposium on Biomechanics and Medicine in Swimming, pp. 249-253, France: University of Saint-Etienne

Li Z. Methodology Research on kinematic parameters analysis during swimming flip turns technical process. Shanghai Sport University, Dissertation for Masters Degree, 2013: 25-30

Lyttle A, Lloyd D, Blanksby B, Elliott B. Optimal Glide Path during the Freestyle flip Turn. J Sci Med Sport, 1999b; 2(4): 413-414

Lyttle AD, Blanksby BA, Elliott BC, Lloyd DG. Investigating kinetics in the Freestyle flip Turn push-Off. J Appl Biomech, 1999a; 15(3): 242-245

Maglischo EW. Swimming fastest. Hum Kinet, 2003: 265-315 
Mason B, Cossor J. What can we learn from Olympic competition analysis at the 1999 Pan Pacific swimming championships? Proceedings of the IXth International Symposium on Biomechanics in Sports: Swimming 2000:75-82

Mason, BR, Sacilotto G, Hazrati P, Mackintosh C. Characteristics of Elite swim Turn performances, Proceedings of the 33rd International Conference on Biomechanics in Sport, Poitiers, France, June 29July3, 2015

Slawson SE, Justham LM, Conway PP, Le-Sage T, West AA. Characterizing the swimming tumble Turn using acceleration data. Proceedings of the Institution of Mechanical Engineers, Part P: Journal of Sports Engineering and Technology 2012; 226(1): 3-15

Yang H. Technical analysis of Chinese and foreign elite female freestyle swimmers in short distances. Sports Sci, 2003; 3: 73-79

Zhang Y. A biomechanical study for optimizing Sun Yang's turning technique during the preparation of London Olympic Games. China Sport Sci, 2013; 9: 85-90

Zheng M. Diagnose and optimization of Pang Jiaying's freestyle skills before the 29th Olympic Games. J Shanghai Univ Sport, 2010; 9: 84-88

Zhu T. Kinetic analysis of turning skills of elite swimmers. Chin Sci Technol Sports, 1993; 6: 42-49

\section{Corresponding author:}

\section{Yuhong Wen}

Beijing Sport University, Beijing, China

Adress: 48, Xinxi Road, Haidian District, Beijing, 100084, China

Phone: +86 (10) 62989098;

Fax: +86 (10) 62989098

E-mail: wyhswim@126.com 